
ARTERITIS

P. Régnier ${ }^{1,2}$, A. Le Joncour ${ }^{1,2}$, A. Maciejewski-Duval ${ }^{1,2}$, A. C. Desbois ${ }^{1,2}$, C. Comarmond ${ }^{1,2}$, M. Rosenzwajg ${ }^{1,2}$, D. Klatzmann ${ }^{1,2}$, P. Cacoub $^{1,2}$

D. Saadoun ${ }^{1,2}$. 'Sorbonne Universités, UPMC Université Paris 6, INSERM, UMR $S$ 959, Immunology-Immunopathology-Immunotherapy (I3), F-75005, Paris, France; ${ }^{2}$ Biotherapy (CIC-BTi) and Inflammation-Immunopathology-Biotherapy Department (DHU i2B), Hôpital de la Pitié-Salpêtrière, AP-HP, F-75651, Paris, France

Background: Takayasu's arteritis (TAK) is a large vessel vasculitis (LVV) in which the aorta and its main branches are greatly inflamed, leading to wall thickening, fibrosis, stenosis and to artery occlusion(1). The disease is more common in women mostly between 20 and 30 years old. TAK has a high morbidity rate: $50 \%$ of patients will relapse within 10 years after diagnosis(2, 3). This inflammation is essentially mediated by infiltration with macrophages and pro-inflammatory Th1/ Th17 effector subsets(4-8). But the mechanisms behind these phenomena are essentially unknown. TAK is mainly treated with non-specific steroids(1) which are associated with potential side effects when used for a long-time course.

Objectives: Our work aims to explore the involvement of JAK/STAT signaling pathway and its downstream biological cascades in pro-inflammatory $T$ cells differentiation and disease activity of TAK. Plus, our work allows to consider targeting the JAK/STAT pathway in TAK using JAK inhibitors (JAKinibs).

Methods: We analyzed transcriptome of FACS-sorted CD4+ and CD8+ T cells from healthy donors (HD) and TAK, using differential gene, pathway and network analysis. Then, we assessed in vitro and in vivo effects of JAKinibs in TAK by flow cytometry (FC).

Results: Transcriptome analysis showed hundreds of significantly dysregulated genes/pathways for CD4+ and CD8+ samples between HD and TAK. Among these, we noticed in TAK a great enrichment for pathways linked to type I and II interferons (IFN), JAK/STAT and cytokines/chemokines-related signaling. We confirmed by RT-qPCR the upregulation of a type I IFN-specific gene signature in TAK T cells as compared to HD. Using genes coming from the previous pathways, we constructed networks connecting them according to their respective protein interactions. This representation showed for both CD4+ and CD8+ T cells that JAK and STAT genes were densely connected, thus representing core genes/proteins in the TAK physiopathology. We then performed in vitro cell cultures of PBMCs from HD or TAK supplemented with Ruxolitinib (JAK1/2 inhibitor) or PBS. We observed by FC that JAKinibs significantly induced in TAK CD4+ and CD8+ T cells reduction of CD25 expression, decrease of Th1/Th17 pro-inflammatory cells and increase of Tregs.

Next, we followed by FC 3 TAK (refractory to conventional treatments) treated with JAKinibs. We also observed in their PBMCs a reduction of CD25 expression by CD4+ T cells, a decrease of Th1 and Th17 cells and an increase of Tregs, accompanied by an increase of the Tregs/Teffs ratio. JAKinibs also decreased C-Reactive Protein level, NIH score and co-administered steroids doses (present before JAKinibs introduction) in these 3 in vivo-treated TAK.

Conclusion: JAK/STAT signaling pathway is critical in the pathogenesis of TAK and JAKinibs may be promising in its treatment.

References:

[1] F. Numano, M. Okawara, H. Inomata, Y. Kobayashi, The Lancet. 356, 10231025 (2000)

[2] C. Comarmond et al., Circulation. 136, 1114-1122 (2017).

[3] A. Mirouse et al., J. Autoimmun. 96, 35-39 (2019).

[4] C. M. Weyand, J. J. Goronzy, Nat. Rev. Rheumatol. 9, 731-740 (2013).

[5] C. M. Weyand et al., Clin. Immunol. 206, 33-41 (2019).

[6] D. Saadoun et al., Arthritis Rheumatol. 67, 1353-1360 (2015).

[7] T. Mirault, H. Guillet, E. Messas, Presse Médicale. 46, e189-e196 (2017).

[8] D. P. Misra, S. Chaurasia, R. Misra, Autoimmune Dis. 2016, 1-8 (2016)

Disclosure of Interests: Paul Régnier: None declared, Alexandre Le Joncour: None declared, Anna Maciejewski-Duval: None declared, Anne-Claire DESBOIS None declared, Cloé Comarmond: None declared, Michelle Rosenzwajg: None declared, David Klatzmann Consultant of: ILTOO Pharma, Patrice cacoub: None declared, David Saadoun: None declared

DOI: 10.1136/annrheumdis-2020-eular.4987

\section{SAT0247 \\ PREDICTORS OF ADVERSE OUTCOMES IN DIFFUSE ALVEOLAR HEMORRHAGE OF IMMUNE AND NON- IMMUNE CAUSES: 12-YEAR EXPERIENCE FROM A UNIVERSITY HOSPITAL}

A. Bhushan ${ }^{1}$, D. Choi ${ }^{1}$, G. Maresh ${ }^{1}$, A. Deodhar ${ }^{1} .{ }^{1}$ Oregon Health \& Sciences University, Portland, United States of America

Background: Diffuse alveolar hemorrhage (DAH) is a rare, life-threatening condition that has either immune or non-immune etiologies1. DAH caused by capillaritis can be immune-mediated (IM-DAH), e.g. anti-neutrophil cytoplasmic antibody (ANCA) vasculitis and systemic lupus erythematosus, but DAH may also result from anticoagulation, heart failure, drugs or inhaled toxins. Since IM-DAH has specific therapies available, we hypothesized that patients with IM-DAH would have a better prognosis.

Objectives: We did a retrospective analysis of all DAH cases seen at our univer sity hospital in the last 12 years to investigate the predictors of adverse outcomes. Methods: Using Epic radiant and Agfa Radiology Information System databases, we queried electronic medical records of all patients admitted to our university between Jan 2007 to Jan 2019 who had the words "diffuse alveolar hemorrhage" in their chest $\mathrm{x}$-ray report. We manually reviewed charts of all these patients to confirm true DAH. True DAH was defined as suspicion of DAH on chest $x$-ray plus inclusion of DAH on the discharge problem list. We did a detailed chart review of true DAH cases to extract information regarding demographics, baseline disease characteristics, physical/serology/imaging findings, treatment received, and outcomes. The outcomes of interest were death, intubation, shock, need for hemodialysis (HD), and red blood cell transfusions. We compared IM-DAH with non IM-DAH cases using descriptive statistics, t-test, and chi-squared tests. We used logistic regression models to assess the influence of baseline characteristics on outcomes. A p-value $<0.05$ was considered statistically significant.

Results: There were 88 cases of DAH (M:F 54:34, median age 57) fulfilling inclusion criteria (Table 1). The non-immune etiology was diagnosed in $63 \%$, while $36 \%$ were IM-DAH (18\% ANCA associated, 9\% SLE, $2 \%$ decompensated heart failure, the rest were others). No clear etiology for DAH was found in $37.5 \%$ cases. Death within 90 days of onset of DAH occurred in $37.5 \%, 5.6 \%$ had recurrent $\mathrm{DAH}$, and $56.8 \%$ had sustained remission. Non-IM DAH cases had worse outcomes such as death and were less likely to experience sustained remission (Chi-squared = 19.1, p < 0.001), though IM-DAH were more likely to receive HD (Chi-squared = 7.5, p-value 0.01). Presence of extrapulmonary findings (e.g. nephritis) was a risk factor for adverse outcome, and was statistically significantly correlated with the amount of blood products received, need for HD and likelihood of death, which did not reach statistical significance. Shock and intubation were associated with a higher likelihood of death ( $p=0.02$ and $p=0.001$, respectively).

Table 1. Comparison of Clinical Characteristics of Immune versus NonImmune Cases of Diffuse Alveolar Hemorrhage

\begin{tabular}{lccc}
\hline Variable & $\begin{array}{c}\text { Immune cases } \\
(\mathrm{N}=32)\end{array}$ & $\begin{array}{c}\text { Non-immune cases } \\
(\mathrm{N}=56)\end{array}$ & $\begin{array}{c}\text { Statistical } \\
\text { comparison }\end{array}$ \\
\hline Age (years) & 51.09 & 55.91 & $\mathrm{P}=0.196$ \\
\%Female & 43.8 & 35.7 & $\mathrm{P}=0.510$ \\
\%presenting with hemoptysis & $8(25 \%)$ & $14(25 \%)$ & $\mathrm{P}=0.101$ \\
\%extrapulmonary findings & $20(62.5 \%)$ & $1(1.7 \%)$ & $\mathrm{P}=6.9^{*} \mathrm{e}^{-10}$ \\
pANCA positive & $16(50 \%)$ & $2(3.6 \%)$ & $\mathrm{P}=0.0004$ \\
\% on anticoagulation & 9.4 & 2.5 & $\mathrm{P}=0.090$ \\
Mean Creatinine & 2.38 & 1.89 & $\mathrm{P}=0.507$ \\
Mean hospital length of stay (days) & 16.69 & 23.27 & $\mathrm{P}=0.139$ \\
Drop in Hemoglobin prior to DAH and & 0.24 & 1.17 & $\mathrm{P}=0.070$ \\
$\quad$ day of DAH & & & \\
\%Bronchoscopy-confirmed DAH & 62.5 & 75.0 & $\mathrm{P}=0694$ \\
Mean units of blood transfused & 1.91 & 2.66 & $\mathrm{P}=0.448$ \\
\%Need for hemodialysis & 37.5 & 12.5 & $\mathrm{P}=0.010$ \\
\%Shock (any kind) & 21.9 & 32.1 & $\mathrm{P}=0.338$ \\
\%Need for intubation & 43.8 & 62.5 & $\mathrm{P}=0.122$ \\
\%Death within 90 days & 12.5 & 52.7 & $\mathrm{P}=0.0009$ \\
\end{tabular}

Conclusion: $\mathrm{DAH}$, a life-threatening condition, has both immune and non-immune etiologies. Our 12-years, single-center, university hospital experience showed that IM-DAH has a better prognosis than non IM-DAH. Presence of extrapulmonary manifestations was associated with worse outcomes.

References:

[1] Moo Suk Park. Diffuse Alveolar Hemorrhage. Tuberc Respir Dis (Seoul). 2013 Apr; 74(4): 151-162.

[2] Nasser M, Cottin V. Alveolar Hemorrhage in Vasculitis (Primary and Secondary). Semin Respir Crit Care Med. 2018 Aug;39(4):482-493.

Disclosure of Interests: Ambika Bhushan: None declared, Dongseok Choi None declared, Guy Maresh: None declared, Atul Deodhar Grant/research support from: AbbVie, Eli Lilly, GSK, Novartis, Pfizer, UCB, Consultant of: AbbVie, Amgen, Boehringer Ingelheim, Bristol Myer Squibb (BMS), Eli Lilly, GSK, Jans sen, Novartis, Pfizer, UCB, Speakers bureau: AbbVie, Amgen, Boehringer Ingelheim, Bristol Myer Squibb (BMS), Eli Lilly, GSK, Janssen, Novartis, Pfizer, UCB DOI: 10.1136/annrheumdis-2020-eular.534

\begin{tabular}{|l|l}
\hline SAT0248 & PATTERNS OF DRUG TREATMENT FOR \\
& MAINTENANCE PHASE OF ANCA-ASSOCIATED \\
& VASCULITIS (AAV) IN REAL WORLD PRACTICE IN \\
& EUROPE - PROLONGED GLUCOCORTICOID USE IS \\
& COMMON AND VARIOUS TREATMENT REGIMES ARE \\
& USED
\end{tabular}

P. Rutherford ${ }^{1}$, D. Götte ${ }^{1}{ }^{1}$ Vifor Pharma, Medical Affairs, Zurich, Switzerland 